\title{
EL «DISCURSO DEL ODIO» Y SU PROHIBICIÓN*
}

\author{
Ricardo Cueva Fernández \\ Universitat Pompeu Fabra
}

RESUMEN. En nuestras sociedades de carácter multicultural contemporáneas existen distintos patrones culturales, así como identidades de carácter dispar y grupos que mantienen sistemas de adscripción diferenciados. Pero este pluralismo no debería hacernos olvidar que ciertas personas, y precisamente por el hecho de pertenecer a determinados colectivos, pueden sufrir de una vulnerabilidad relevante que les impida actuar libremente en su vida habitual o en el foro democrático. En este sentido, el discurso del odio articula una agresión contra ellas, de modo que resultarían justificadas ciertas limitaciones a la libertad de expresión para frenarlo.

Palabras clave: discurso del odio, libertad de expresión, igualdad, daño, democracia deliberativa.

ABSTRACT. In our contemporary multicultural societies there are several cultural patterns of and disparate identities and groups who hold different attachment systems. But this pluralism should not obscure the fact that some people, and precisely because they belong to certain groups, may have a significant vulnerability that prevents them from acting freely in their normal life or in the democratic forum. In this sense, hate speech articulates an attack against them, and to stop it would be justified to set some limits on freedom of expression.

Keywords: hate speech, freedom of speech, equality, harm, deliberative democracy.

* Fecha de recepción: 7 de noviembre de 2011. Fecha de aceptación: 18 de diciembre de 2011. 


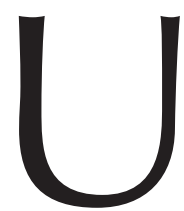

n famoso diseñador defiende, en visible estado de embriaguez, la conducta genocida nazi. Una manifestación en España exhibe pancartas pidiendo la expulsión de inmigrantes por el único motivo de pertenecer a cierta nacionalidad. Tal petición resulta amparada también por un candidato electoral que además los identifica con la delincuencia de forma directa. Algunos vecinos de determinada localidad se manifiestan exigiendo la expulsión de otros que pertenecen a distinta etnia. Un clérigo sostiene justificaciones para el maltrato a las mujeres. Y así podríamos continuar enumerando muchas y diversas manifestaciones de un mismo fenómeno que se va abordar en las siguientes líneas.

Las últimas décadas han presenciado una preocupación mayor por las consecuencias de cierto discurso a caballo entre lo político y lo meramente visceral, conocido como hate speech o discurso del odio. Se trataría de cualquier forma de expresión (mediando la palabra hablada o escrita, e incluso el gesto, el símbolo o la representación), cuyo propósito fuera el de discriminar, menoscabando su dignidad, a un grupo social o a sus miembros por su sola pertenencia al mismo. Usualmente, pues, va dirigido contra individuos distinguibles por motivo de su etnia o raza, religión, género u orientación sexual, aunque tal clasificación haya ido ampliándose ${ }^{1}$.

Este lenguaje que oscila entre lo intimidatorio y lo humillante, opuesto a las comunidades de carácter democrático y multicultural, tiene una presencia vetusta entre nosotros, pero la extensión de fenómenos genocidas durante el siglo XX ha contribuido a abordarla hoy de manera diferente. En los últimos años se han producido además numerosos incidentes relacionados con las actitudes intimidatorias contra escritores, periodistas, o colectivos identificados por su procedencia foránea o religiosa, que junto con atentados y ataques terroristas de uno u otro signo han vapuleado a los diversos países europeos hasta extremos hasta ahora desconocidos. Todas estas conductas delictivas, unas veces con una rabia e intensidad que sólo pueden provenir del fanatismo más cruel, y otras de un odio repleto de connotaciones ideológicas, tienen como característica común su acometida contra grupos enteros de personas.

Los organismos europeos han reaccionado en diversas ocasiones frente a esta situación a través de varias Recomendaciones y siguiendo así la senda del art. 20.2 perteneciente al Pacto Internacional de Derechos Civiles y Políticos de 16 de diciembre de 1966 («toda apología del odio nacional, racial o religioso que constituya incitación a la discriminación, la hostilidad o la violencia estará prohibida por la Ley»). Pero esto

1 Para Sumner, sería «cualquier forma de expresión cuyo propósito principal sea el de insultar o denigrar a los miembros de un grupo social identificado por características tales como su raza, etnia, religión o orientación sexual, o para despertar enemistad u hostilidad contra él» (L. W. SuMNER, «Incitement and the Regulation of Hate Speech in Canada: A Philosophical Analysis», en I. HARE y J. WeINSTEIN, Extreme Speech and Democracy, New York, Oxford University Press, 2009, 207 y 208). Otros se refieren a la «conducta expresiva capaz de, o encaminada a, inculcar o incitar al prejuicio contra una persona o grupo de personas, y sobre un supuesto específico, incluyendo aquí la raza, nacionalidad, etnia, religión, sexualidad, identidad de género o género propiamente dicho» (K. GELBER, «Freedom of political speech, hate speech and the argument from democracy: The transformative contribution of capabilities theory», Contemporary Political Theory, 9, 3, 2010, 305). «Expresa, defiende, anima, promueve o incita al odio contra un grupo de individuos identificables por un rasgo o un conjunto de rasgos» (B. PAREKH, «Hate speech: Is there a case for banning?», Public Policy Research, 12, 4, 2005 , 214). Evidentemente, el que la definición sea más o menos amplia o tenga tal o cual contenido vienen de la mano de una perspectiva previa sobre las medidas que se deben tomar para combatir el bate speech. 
conforma, además, tan sólo una pequeña parte de la normativa internacional relativa al tema que nos ocupa, pues también han de considerarse documentos como la Convención Internacional sobre la Eliminación de todas las Formas de Discriminación Racial (21 de diciembre de 1965, art. 4) ${ }^{2}$.

El Estado español, de acuerdo con la trayectoria marcada en la Unión Europea, y reuniendo asimismo derecho que ya se había incluido tradicionalmente en nuestro ordenamiento, tipifica varias infracciones penales relativas al hate speech en diversos artículos del Código Penal. Entre los principales han de señalarse:

1. El art. 510.1. Prohibición de provocar «a la discriminación, al odio o a la violencia contra grupos o asociaciones, por motivos racistas, antisemitas u otros referentes a la ideología, religión o creencias, situación familiar, la pertenencia de sus miembros a una etnia o raza, su origen nacional, su sexo, orientación sexual, enfermedad o minusvalía».

2. El segundo apartado del mismo precepto castiga a aquellos «que, con conocimiento de su falsedad o temerario desprecio hacia la verdad, difundieren informaciones injuriosas sobre grupos o asociaciones en relación a su ideología, religión o creencias, la pertenencia de sus miembros a una etnia o raza, su origen nacional, su sexo, orientación sexual, enfermedad o minusvalía».

3. Art. 170.1: reprime las «amenazas de un mal que constituyere delito», cuando «fuesen dirigidas a atemorizar a los habitantes de una población, grupo étnico, cultural o religioso, o colectivo social o profesional, o a cualquier otro grupo de personas y tuvieran la gravedad necesaria para conseguirlo», estableciendo así un tipo agravado de las amenazas.

4. Art. 607.2: es delito «la difusión por cualquier medio de ideas o doctrinas que justifiquen los delitos tipificados en el apartado anterior de este artículo [los relativos al genocidio], o pretendan la rehabilitación de regímenes o instituciones que amparen prácticas generadoras de los mismos».

Por supuesto, existen otros tipos penales más o menos conectados a los que aquí se indican, pero que desbordarían el área de nuestra investigación ${ }^{3}$. Aunque sí interesa recordar a los efectos de la presente exposición el delito de calumnia de los arts. 205207 y el de injuria de los arts. 208-210, así como el art. 22 ( «las asociaciones que persigan fines o utilicen medios tipificados como delito son ilegales») y el 18, con un

2 «Los Estados partes condenan toda la propaganda y todas las organizaciones que se inspiren en ideas o teorías basadas en la superioridad de una raza o de un grupo de personas de un determinado color u origen étnico, o que pretendan justificar o promover el odio racial y la discriminación racial, cualquiera que sea su forma, y se comprometen a tomar medidas inmediatas y positivas destinadas a eliminar toda incitación a tal discriminación o actos de tal discriminación, y, con ese fin, teniendo debidamente en cuenta los principios incorporados en la Declaración Universal de Derechos Humanos, así como los derechos expresamente enunciados en el art. 5 de la presente Convención».

3 Así, el art. 523 (cometerá delito «el que con violencia, amenaza, tumulto o vías de hecho, impidiere, interrumpiere o perturbare los actos, funciones, ceremonias o manifestaciones de las confesiones religiosas»), el art. 524, que castiga a quien «en templo, lugar destinado al culto o en ceremonias religiosas ejecutare actos de profanación en ofensa de los sentimientos religiosos». O el art. 525.1 (serán castigados «los que, para ofender los sentimientos de los miembros de una confesión religiosa, hagan públicamente, de palabra, por escrito o mediante cualquier tipo de documento, escarnio de sus dogmas, creencias, ritos o ceremonias, o vejen, también públicamente, a quienes los profesan o practican») y el art. 615 («la provocación, la conspiración y la proposición para la ejecución de los delitos» contra la comunidad internacional). 
primer apartado referente a la provocación («existe cuando directamente se incita por medio de la imprenta, la radiodifusión o cualquier otro medio de eficacia semejante, que facilite la publicidad, o ante una concurrencia de personas, a la perpetración de un delito») y a la apología (es decir, «la exposición, ante una concurrencia de personas o por cualquier medio de difusión, de ideas o doctrinas que ensalcen el crimen o enaltezcan a su autor») ${ }^{4}$.

La prohibición de estos comportamientos en el Código Penal español obedecería a tres tipos de protección frente al hate speech:

- la que impide la promoción del odio, violencia o discriminación contra ciertos grupos,

- la que impide la calumnia o injuria contra ellos,

- la que prohíbe la injuria contra cualquiera por razón de su pertenencia a tales grupos 5 .

Valga, pues, la exposición realizada para el hate speech en relación con el análisis que se va a realizar en el presente artículo. El Código Penal español se ha situado frente a numerosas conductas más o menos relacionadas con el discurso del odio, al margen de la normativa de orden público o antidiscriminatoria que pueda existir también en otros ámbitos no penales y que tampoco conviene obviar aquí. Sin llegar a los extremos contundentes de la sanción punitiva alemana o francesa vigentes en la actualidad, se halla en concordancia con los ordenamientos de nuestro entorno, que se sitúan a su vez dentro de los límites fijados por la jurisprudencia del Tribunal Europeo de Derechos Humanos, basándose en el Convenio Europeo para la Protección de los Derechos Humanos y de las Libertades Fundamentales de 20 de marzo de $1952^{6}$.

Pero la respuesta europea al hate speech no es la única existente entre los países democráticos. Así, y muy a pesar de los decididos impulsos de organismos internacionales como la ONU para que se adopten medidas que puedan frenar su extensión, los Estados Unidos de América continúan resistiéndose a tal empuje, basándose para ello en una doctrina de su Tribunal Supremo que pretende proteger de forma enérgi-

4 Considerándose, asimismo, que «la apología sólo será delictiva como forma de provocación y si por su naturaleza y circunstancias constituye una incitación directa a cometer un delito». Y añadiéndose que (segundo apartado) «la provocación se castigará exclusivamente en los casos en que la Ley así lo prevea. Si a la provocación hubiese seguido la perpetración del delito, se castigará como inducción».

5 Una definición que coincide básicamente con la presentada por la profesora BRISON: «Entiendo por hate speech el discurso que, dirigido contra individuos o grupos sobre la base de características como la raza, el sexo, la etnia, la religión o la orientación sexual: 1) constituya humillación directa (face-to-face vilification), 2) cree un ambiente hostil o intimidatorio, o 3) sea una difamación colectiva (group libel)». S. J. BRISON, «The Autonomy Defense of Free Speech», Ethics, 108, 2, 1998, 313.

6 El art. 10.2 del Convenio reconoce la libertad de expresión (incluyendo el derecho a manifestar opiniones y a recibir y transmitir información e ideas), estableciendo asimismo que puede quedar sometido a restricciones «siempre que estén previstas en la ley y sean necesarias en una sociedad democrática en interés de la seguridad nacional, la integridad territorial o la seguridad pública, para la prevención del desorden o el delito, para la protección de la salud o la moral, para la protección de la reputación de otros, para la prevención de la revelación de información confidencial, o para el mantenimiento de la autoridad e imparcialidad judicial». Estas amplias facultades a favor de los Estados quedaron luego sujetas a los límites jurisprudenciales de una serie de sentencias del TEDH: Handyside vs. Reino Unido, 1 EHRR (1979), 737; Sunday Times vs. Reino Unido, 2 EHRR (1980), 245; Lingens vs. Austria, 8 EHRR (1986), 407; Castells vs. España, 14 EHRR (1992), 345; Thorgeison vs. Islandia, 14 EHRR (1992), 843; Jersild vs. Dinamarca, 19 EHRR (1994), 1; Oberschlick vs. Austria, 19 EHRR (1995), 389. 
ca la libertad de expresión ${ }^{7}$. Y es que también la nación norteamericana reconoce la existencia de un discurso del odio, pero se diferenciaría de sus democracias vecinas, incluida la canadiense, en ser altamente reticente, si no contraria, a prohibirlo de forma legal ${ }^{8}$. Los argumentos que aporta su doctrina son muy numerosos, y a menudo seguidos, como no podía ser menos, por autores, no sólo británicos, sino también de otras naciones europeas, proclives a la despenalización de ciertas conductas que se encuentran ahora sometidas a sanción en el viejo continente y en general a evitar a toda costa restricciones a la libertad de expresión que puedan considerase innecesarias. Dentro de esta postura pueden entresacarse varios argumentos sostenidos por eminentes constitucionalistas, criminólogos, penalistas y iusfilósofos, a su vez rebatidos por otros académicos de idéntica condición 9 . Para el presente estudio he resuelto seleccionar los argumentos más destacables en el debate que me ocupa.

\section{LOS PRINCIPALES ARGUMENTOS CONTRA LA PROHIBICIÓN DEL HATE SPEECH}

Frente a las posibles restricciones de discursos y manifestaciones o de mensajes en general, cierto número de autores ha erigido la libertad de expresión como principio que implicaría considerarlas ilegítimas. Se generaría así una presunción contra cualquier tipo de prohibición al respecto, aun cuando fuera dirigida a frenar actuaciones dañinas ${ }^{10}$. Por decirlo en palabras de RAWLS, se trataría de una de las «libertades básicas», y por tanto gozaría de especial preeminencia. Esta postura genérica se concretaría a su vez en otra más específica y opuesta a la restricción del «discurso del odio» entendido como correspondiente a las conductas arriba señaladas. La clasificación sobre los distintos argumentos que apoyarían esta posición puede variar ${ }^{11}$, pero en general hay una coincidencia en apuntar a tres de ellos como especialmente destacables, ya que cada uno tendría por separado su propio perfil. Se trataría de los argumentos de la autonomía, el de la democracia y el del mercado de las ideas.

El primero de ellos, también denominado «derecho a la independencia moral» por R. DwORKIN ${ }^{12}$, vendría a sostener que limitaciones a la libertad de expresión como las

7 G. Lippman y M. H. REDISH, «Freedom of Expression and the Civic Republican Revival in Constitutional Theory: The Ominous Implications», California Law Review, 79, 2, 1991, 281-283.

${ }^{8}$ Sobre las limitaciones a la libertad de expresión en la jurisprudencia estadounidense, vid. S. J. BRISON, «The Autonomy Defense of Free Speech», op. cit., 318. Entre las más obvias estarían las referentes a la difamación de individuos o la publicidad engañosa. Para un cuadro comparativo sobre la jurisprudencia estadounidense y la canadiense, vid. S. L. NEwMAN, «Liberty, Community, and Censorship: Hate Speech and Freedom of Expression in Canada and the United States», American Review of Canadian Studies, 32, 2002, 3.

9 Para hacerse una idea más o menos fiel, consúltese la propia bibliografía que aparece al final del artículo.

${ }^{10}$ F. SCHAuer, Free Speech. A Philosophical Enquiry, Cambridge, Cambridge University Press, 1982, 8: «Bajo un principio de libertad de expresión, cualquier actuación gubernamental dirigida a conseguir un objetivo, sea positivo o negativo, debe suministrar una justificación más fuerte cuando la consecución de tal fin exija la restricción de la expresión que cuando no se apliquen limitaciones a la misma». Otro autor adscrito a esta premisa es T. SCANLON, «A Theory of Freedom of Expression», Philosophy and Public Affairs, 1, 2, 1972, 204.

${ }^{11}$ S. J. BRISON, «The Autonomy Defense of Free Speech», op. cit.; C. YONG, «Does Freedom of speech include hate speech?», Res Publica, 17, 2011, 4; S. SORIAL, «Free Speech, Autonomy and the Marketplace of Ideas», Journal of Value Inquiry, 44, 2010, 2.

${ }_{12}$ R. Dworkin, A matter of principle, Oxford, Clarendon Press (1. ${ }^{a}$ ed. de 1985, Cambridge, Harvard University Press), 1986, 364. 
relativas al hate speech provienen de una suerte de autoritarismo que no trataría a los ciudadanos como libres e iguales, al imponerles determinados criterios y privar de su capacidad de decisión tanto al emisor como al receptor del mensaje ${ }^{13}$. «Las personas tienen el derecho a no sufrir desventaja en la distribución de los bienes y oportunidades sociales [...] sólo sobre la base de que sus funcionarios o conciudadanos piensen que sus opiniones sobre la manera correcta de conducir sus vidas resultan innobles o erróneas» ${ }^{14}$. La prohibición del hate speech permitiría al Estado delimitar el contenido del discurso que puede autorizarse, atribuyéndole un excesivo poder que violaría su necesaria neutralidad moral acerca de las distintas opiniones existentes en la sociedad ${ }^{15}$ y poniendo en peligro la libertad de los ciudadanos ${ }^{16}$. Similar a esta posición sería la de quienes rechazan también idénticas limitaciones basándose en el valor de la autorrealización individual: «Las restricciones sobre lo que le resulta permitido decir o escribir a alguien, escuchar o leer, inhibe el crecimiento de su personalidad. Los individuos no serán capaces de desarrollarse intelectual y espiritualmente, a menos que sean libres de formular sus creencias y actitudes políticas a través de la discusión pública y en respuesta a la crítica de otros» ${ }^{17}$.

La segunda postura principal mencionada frente a la prohibición del hate speech es la que se apoya en el denominado «argumento de la democracia». Esta senda fue iniciada por A. MEIKLEJOHN, quien ya en 1948 unía tal régimen político con la libertad de expresión (Free Speech and its Relationship with Self-government). Vendría a afirmar que las limitaciones de esta última conducirían a impedir el normal desenvolvimiento de proceso democrático, que requiere el conocimiento de todos los puntos de vista en conflicto $^{18}$. De esta forma quedaría minada la legitimidad del sistema político, que exige que todos sean escuchados por igual ${ }^{19}$.

En tercer lugar, algunos autores, y siguiendo a J. STUART MiLl (principalmente el capítulo II de su On Liberty), acuden a otro argumento que podríamos denominar «epistémico». De acuerdo con tal postura, en un «libre mercado de las ideas» las opiniones verdaderas tenderán a encontrar el apoyo de la sociedad y prevalecerán sobre las falsas. Esta es la posición mantenida por el magistrado Oliver W. Holmes en su famoso voto disidente de la sentencia del Tribunal Supremo estadounidense Abrams vs. United States (1919), en donde vino a sostener que el mejor test para probar la veracidad de un pensamiento estribaba en el propio poder de éste para ser aceptado de entre todos los que se presentaran en libre concurrencia ${ }^{20}$. El «libre mercado de las ideas» permitiría así obtener la verdad, siempre que no interviniera en él autoridad pública alguna.

13 T. NAgEL, «Personal Rights and Public Space», Philosophy \& Public Affairs, 24, 2, 1995,96 y 97.

${ }_{14}$ R. DworkIN, A matter of principle, op. cit., 1986, 353. La cursiva es propia.

15 J. WeinsteIn, «Extreme Speech, Public Order, and Democracy: Lessons from the Masses», en Extreme Speech and Democracy, op. cit., 82-86.

${ }^{16}$ C. E. BAKER, «Autonomy and Hate Speech», en Extreme Speech and Democracy, op. cit., 154.

17 E. BARENDT, Freedom of Speech, Oxford, Clarendon Press, 1985, 14.

18 J. WeinsteIn, «Extreme Speech, Public Order, and Democracy: Lessons from the Masses», en Extreme Speech and Democracy, op. cit., 25-30, 47 y 48, y 61.

19 En esto insiste ibid., 49.

20 Abrams vs. United States, 250 U. S. 616, 624-631 (1919). Nótese que esta opinión fue formulada en un caso en el que la mayoría del Tribunal optó por condenar a un procomunista que había difundido octavillas contra la intervención estadounidense en la Primera Guerra Mundial. 
Empezando por las críticas a este último argumento, que han sido numerosas ${ }^{21}$, algunas se basan en premisas empíricas y otras en algunas de carácter sustantivo. Entre las primeras, destacan aquellas que señalan la inexistencia de un mercado perfecto de las ideas en nuestras sociedades, dadas las articulaciones de grupos dominantes en ellas y que parten de condiciones aventajadas ${ }^{22}$. De otra parte, algunos consideran que la verdad no tiene por qué ser el principal valor social, ni gozar de prioridad sobre cualquier otro o por encima de diversos intereses ${ }^{23}$. Los hay que señalan que la analogía con el mercado es incorrecta: éste sería un mecanismo dirigido a conseguir eficiencia, pero no justicia distributiva, y no parece que tengamos criterio alguno para identificar la «verdad» con uno de los dos ${ }^{24}$. Además, si se percibe que los consumidores de tal mercado tenderían a «adquirir» ideas según sus intereses, lo único que prevalecería en este ámbito sería el interés de la mayoría, pero no la verdad ${ }^{25}$. En todo caso, lo más importante a subrayar aquí es que el argumento indicado sólo tendría validez además en tanto en cuanto los sujetos tuvieran la posibilidad de disponer de información perfecta sobre ese mercado de las ideas y de actuar libremente a la hora de aportar y escoger las opciones existentes en él. Es decir, que nos devuelve al problema de la autonomía personal ${ }^{26}$. Como núcleo fuerte de la discusión entre los autores, en realidad es el que permanece. Conviene aclarar ya, pues, varios aspectos sobre tal asunto.

En primer lugar, parece claro que la libertad de expresión no se refiere sólo al ámbito político. En el arte, la literatura, la conversación en la plaza pública, el gesto o la mueca, el ser humano también encuentra formas de expresarse que no pueden relacionarse de forma directa con los derechos de participación política ${ }^{27}$. Desde luego, si se insistiese en la relevancia particular de la libertad de expresión para la democracia, resultaría posible buscar una clasificación de fórmulas que abarcara sólo ciertos terrenos (pongamos por caso, las campañas electorales o las instituciones representativas o los partidos). Pero esto sería una tarea forzada; resulta muy difícil mantener la categoría de una suerte de discurso público separado de otro que no alcanzaría la arena política, porque ¿cuándo entenderíamos que se ha llegado a esta última? Mensajes con escasa repercusión inicial pueden al día siguiente ser voceados por miles de medios, institucionales o no, políticos o asociativos, y más en una época como la nuestra, en la cual los medios de comunicación se han diversificado por obra y gracia de las nuevas tecnologías.

${ }_{21}$ S. J. BRISON, «The Autonomy Defense of Free Speech», op. cit., 334; J. WALDRON, «Dignity and defamation: The visibility of hate», op. cit., 1638 y 1639, B. PAREKH, Hate speech. Is there a case for banning?, op. cit., 2006, 219; S. InGBER, «The Marketplace of Ideas: A Legitimizing Myth», Duke Law Journal, 1984, 1, passim.

${ }_{22}$ S. J. BRISON, «The Autonomy Defense of Free Speech», op. cit., 339; S. INGBER, «The Marketplace of Ideas: A Legitimizing Myth», op. cit., 17; R. Delgado y J. Stefancic, Must We Defend Nazis? Hate Speech, Pornography, and the New First Amendment, New York, New York University Press, 1997, passim.

${ }_{23}$ F. SCHAuer, Free Speech. A Philosophical Enquiry, op. cit., 23; J. FeINBERG, «Limits to the Free Expression of Opinion», en J. FeINBERG y H. Gross (eds.), Philosophy of Law, Encino, Dickenson, 1975, 138. 1639.

24 J. WALDRON, «Dignity and defamation: The visibility of hate», en Harvard Law Review, 123, 7, 2009,

25 S. J. Heyman, «Hate Speech, Public Discourse, and the First Amendment», en I. Hare y J. WeinsteIn, Extreme Speech and Democracy, op. cit., 2009, 170.

26 S. J. BRISON, «The Autonomy Defense of Free Speech», op. cit., 333, quien alude a su vez para respaldar su argumento a $G$. DwORKIN.

$27 \mathrm{Al}$ respecto, J. COHEN habla de intereses expresivos, deliberativos e informativos ( «Freedom of Expression», Philosophy \& Public Affairs, 22, 3, 1993, 223). 
Lo que en realidad tienen en común todas las formas de expresión, así, resulta ser su proyección social, pues cualquiera de ellas pretenden dirigirse a alguna audiencia, ya sea de carácter amplio o de tipo reducido. Y poseyendo tal rasgo pueden entrar en el campo del derecho y sus restricciones, en la medida en que vulneren la libertad de otros o les causen algún mal. Que la entidad del daño originado sea cuantificada de tal o cual manera, o atendiendo a estos o aquellos parámetros, es lo relevante, con el fin de que hallemos en qué medida perjudica a la autonomía personal. Un valor que, aunque también los incluya, no se refiere sólo a los derechos de participación política. Y es que aunque éstos son los que mejor ensamblan, los que mejor reconocen aquélla en la esfera colectiva del autogobierno ${ }^{28}$, no son los únicos que la sostienen ${ }^{29}$, como confirma el catálogo de derechos de cualquier Constitución al estilo de la nuestra. De hecho resulta posible asimismo que ni la facultad de participación política ni otros derechos del ordenamiento resulten atribuidos a todos los sujetos a quienes se reconoce autonomía moral, con lo cual el argumento «democrático» quedaría en entredicho. Por tanto, pasaré a exponer qué elementos pueden influir en el respeto a este valor de modo que harían necesarias algunas restricciones a las expresiones que cayeran dentro del discurso del odio. Se trataría de una categoría sociológica y del análisis de las funciones que cumple el lenguaje en la comunicación humana. Para introducirme en el primer aspecto me detendré además previamente en la regulación penal española sobre el asunto.

\section{EL GRUPO BAJO PROTECCIÓN}

El primer inciso del art. 607.2 del Código Penal español se refiere a «la difusión por cualquier medio de ideas o doctrinas que justifiquen» el delito de genocidio, es decir, a su apología, figura contemplada en el art. 18 a su vez de forma genérica. La conducta genocida supone una infracción gravísima, pues no prescribe (art. 131.2), y sería la cometida por aquellos «que, con propósito de destruir total o parcialmente a un grupo nacional, étnico, racial o religioso», «mataran a algunos de sus miembros», les «agredieran sexualmente», mutilaran o lesionaran, les sometieran «a condiciones de existencia que pongan en peligro su vida o» perturbaren «gravemente su salud», o «llevaran a cabo desplazamientos forzosos del grupo o de sus miembros, adoptaran cualquier medida que tienda a impedir su género de vida o reproducción, o bien trasladaran por la fuerza individuos de un grupo a otro» (art. 607.1 del Código Penal español) ${ }^{30}$. El art. 607.2 merece poco comentario añadido, pues se refiere a las meras condiciones de supervivencia física de colectivos humanos y alude diáfanamente a los acontecimientos históricos más estremecedores del siglo Xx. Resulta relativo a la prohibición de políticas eliminacionistas que atacan la vida y la integridad física de poblaciones enteras. Fuera de este tipo de fuente universal, es decir, aplicable a cualesquiera situa-

28 O como sostiene MARTÍ, el tránsito de un conjunto de preferencias individuales a una función de preferencias colectivas reflejadas en la decisión final (J. L. MARTí, La república deliberativa, Madrid, Marcial Pons, 2006, 45).

29 Esto conduce a C. E. BAKER a rechazar el énfasis en este enfoque, y ampararse en la autonomía personal («Autonomy and Hate Speech», en Extreme Speech and Democracy, op. cit., 146). Pero lo hace desde una posición formalista y no sustantiva, como él mismo señala (ibid., 142), la cual será discutida a continuación.

30 Las cursivas son propias. 
ciones, países y regímenes, necesario para un mínimo respeto a los derechos humanos y la convivencia planetaria, la prohibición del discurso del odio se mueve en el rechazo de conductas que no intentarían tanto, al menos en principio, la destrucción de colectivos, como su subordinación.

En este otro campo, y de acuerdo con la clasificación citada unas páginas más atrás, lo primero que observamos al referirnos a las restricciones penales del bate speech en ordenamientos como el nuestro es que buena parte de ellas en realidad son especificaciones de otros tipos básicos. Tal supuesto puede advertirse claramente en el caso de las injurias y calumnias (art. 510.2, y por extensión, el art. 607.2 en su segundo inciso, respecto a los arts. 205 y 208, que amparan el derecho al bonor y la reputación), así como en el de amenazas (art. 170 en relación con el art. 169, que protege la libre formación de la voluntad o el sentimiento de tranquilidad del sujeto) ${ }^{31}$. Los bienes jurídicos cobijados en unos y otros supuestos tendrían idéntica raíz, diferenciándose por predicarse o no respecto a un colectivo como víctima potencial.

Más problemático en nuestro Código es el tipo del art. 510.1, también acogido en países de nuestro entorno, y referido a la provocación «a la discriminación, al odio o a la violencia contra grupos o asociaciones por motivos racistas, antisemitas u otros referentes a la ideología, religión o creencias, situación familiar, la pertenencia de sus miembros a una etnia o raza, su origen nacional, su sexo, orientación sexual, enfermedad o minusvalía». Esta norma se parecería a las anteriores citadas por pretender la protección de ciertos grupos, pero en este caso no existe un tipo básico del que sea especificación.

¿Por qué la normativa penal debe proteger grupos frente a ciertas conductas no estrictamente eliminacionistas, por qué no quedarse sólo con el art. 610.2 y olvidarse de los otros preceptos, al fin y al cabo sólo especificaciones de otros más tradicionales? Cabe preguntarse entonces quiénes resultarían perjudicados por tal medida. Antes que nada debemos considerar es que a menudo códigos como el nuestro no protegen propiamente grupos en abstracto sin más razones añadidas, sino que lo que ocurre es que a veces lo hacen con respecto a determinados individuos que revisten cierta condición, que implicaría a su vez una vulnerabilidad, alguna indefensión en particular. Tal es el caso del Título XV del CP español («delitos contra los derechos de los trabajadores») o del XV bis («contra los derechos de los ciudadanos extranjeros»). La orientación del ataque que potencialmente puedan sufrir tales personas, en consecuencia, debería suponer un tipo de protección u otra. Se trataría de grupos «visibles» socialmente, con un rasgo atribuible de manera más o menos inmediata al individuo de que se trate.

Ahora bien, lo que a continuación debe uno preguntarse, es cómo podría medirse la vulnerabilidad de tales sujetos. La falta de superioridad numérica no es buen indicador, resultando insuficiente por el motivo de que existen numerosos ejemplos históricos, e incluso actuales, de minorías fuertemente organizadas y que disfrutan de posiciones de poder sobre las mayorías, algo a lo que a menudo contribuyen las divisiones o el aislamiento territorial. Así que una primera pauta para construir una noción de vulnerabilidad nos la proporcionaría la de que el colectivo de que se tratase estuviera «señalado» por prejuicios fuertemente arraigados en la sociedad (contexto diminuyen-

31 Según se trate de amenazas que sean condicionales o no. 
te previo). En particular, asimismo, la visibilidad mayor o menor puede determinar una amenaza más grande en el caso de la «incitación al odio, la discriminación y la violencia», un delito «de clima» que puede desembocar en la amenaza a la seguridad personal ${ }^{32}$. En todas estas direcciones parecen apuntar, por cierto, los instrumentos internacionales como la Convención antes citada contra la discriminación Racial o el Convenio sobre la Eliminación de todas las Formas de Discriminación contra la Mujer, hecho en New York el 18 de diciembre de $1979^{33}$. En el hate speech la asimetría de poder no es contingente o producida por la coincidencia, sino más bien un rasgo sistémico del contexto del mundo en el cual dicho discurso aparece ${ }^{34}$. Esto permitiría interpretarlo como compuesto de actos del habla o similares dirigidos a la subordinación más o menos inmediata.

Una segunda pauta para valorar la vulnerabilidad sería la titularidad más o menos amplia de derechos. Como es de conocimiento común, ciertas personas, por motivo de su pertenencia a un grupo determinado carecen de una ciudadanía completa, es decir, de los derechos de los que sí disfrutan aquellos a quienes se reconoce de forma plena. Así sucede con los niños y los discapacitados, por razones obvias y justificables, y considerando que en épocas pasadas no disponían de casi ningún derecho, mientras que hoy se intenta graduar su posesión atendiendo a criterios objetivos. Pero también en otros casos en los cuales tales motivos no han sido defendibles o, cuanto menos, no de forma tan evidente. Tal supuesto puede percibirse en los casos de residencia más o menos continuada de extranjeros en territorio nacional, por no recordar otros ya del pasado en sociedades como la nuestra, como los de las mujeres o los homosexuales. Esa acotación excluyente ha impedido que tales personas hayan sido o sean tratadas como iguales en la comunidad, resultándolo más o menos según se encuentren recortadas sus facultades en un número mayor de ámbitos, como en el espacio de la deliberación democrática, que es el de los derechos de participación política y de las libertades de expresión, manifestación, reunión y asociación.

\section{EL DAÑO Y LAS PALABRAS}

Sin embargo a toda esta perspectiva sobre la existencia de prejuicios sociales o la visibilidad o sobre la titularidad recortada de facultades por su pertenencia a determinado colectivo, se le podría oponer la que entendiera que hay una clara diferencia entre las palabras o la expresión en general y la conducta. Es decir, la postura que acoge la idea de que una cosa son aquéllas y otras los actos, sin entrar en más consideraciones. «Las palabras no son equivalentes a palos y piedras» ${ }^{35}$, sería el aforismo que sintetiza-

32 Y ello al margen de que no parezca posible castigar, como en cambio el primer inciso del citado art. 510.1 CP, la provocación al «odio». Vid., en tal sentido, L. JERICó, «El caso del Imán de Fuengirola: ¿auténtica comisión del delito de provocación a la violencia (art. 510.1 CP)?», Revista Penal, 18, 2006, 166, y L. W. SuMNER, «Incitement and the Regulation of Hate Speech in Canada: A Philosophical Analysis», en Extreme Speech and Democracy, op. cit., 220.

33 Bien que las medidas que alientan dichos textos no tengan por qué ser exclusivamente penales.

${ }^{34}$ K. GeLber, Speaking Back: The Free Speech versus Hate Speech Debate, Philadelphia, John Benjamins, 2002,87 .

35 «Los palos y piedras pueden romper tus huesos, pero las palabras nunca te herirán. O al menos eso nos inculcaron nuestros padres cuando teníamos siete años». F. SCHAUER, «Uncoupling Free Speech», Columbia 
ría esta manera de pensar ${ }^{36}$. Es cierto que el mayor o menor alejamiento de la fuente del daño debería suponer en consonancia una graduación de la pena, la sanción o el remedio, pero esto no significa que las palabras no tengan a veces efectos muy similares a los de los actos, al menos en el receptor del discurso. Podríamos referirnos así a sus efectos «perlocucionarios» ${ }^{37}$. Voy a detenerme brevemente en este punto.

J. L. Austin criticó en su How Do Things with Words ${ }^{38}$ la distinción habitual entre expresión y acto, así como, en el seno de la primera, entre la performativa y la constativa (la primera implicando a un acto determinado cuando concurrieran con ella varios elementos, como en una ceremonia nupcial, y la segunda tan sólo de carácter descriptivo) ${ }^{39}$. Realizó en su lugar una clasificación tripartita de la expresión, que se dividiría en locucionaria, ilocucionaria y perlocucionaria. La primera, simplemente, poseería un significado. La segunda expresaría una creencia y la tercera supondría inducir al oyente a creer algo. Es decir, respectivamente se expresa una proposición, se articula una creencia y se induce al oyente a tener alguna. El problema es que estas posibilidades se pueden solapar en la misma expresión, que al margen de ser locucionaria puede también gozar de contenido ilocucionario y/o perlocucionario ${ }^{40}$. Puede ser interpretada como una amenaza, una advertencia, una predicción e incluso una promesa; de manera que no podemos averiguar sus implicaciones sin conocer el contexto y las circunstancias de su emanación ${ }^{41}$. En cualquier caso, queda muy claro que la expresión puede inducir a conductas, reacciones e incluso estados de ánimo o creencias. Y lo más temible es que podría desembocar en un efecto silenciador muy similar al de una mordaza en muchos casos ${ }^{42}$, en concreto en aquellos en los que estemos ante la presencia de grupos vulnerables. Estaríamos en situaciones algo distintas que las de un mero daño psicológico inmediato ${ }^{43}$, e incluso cuantificable, del hate speech ${ }^{44}$. Sus víctimas aquí se hallarían sumergidas en una atmósfera de temor, rodeadas de un peligro que iría desde la amenaza a la seguridad personal (miedo a represalias por cualquier actuación que irritara a los difusores del discurso del odio), hasta su marginación de actividades sociales diversas (asistencia a eventos o espectáculos, a lugares de ocio, o, simplemen-

Law Review, 92, 1992, 147; y también lo cita en el mismo sentido, L. ALEXANDER, «Banning Hate Speech and the Sticks and Stones Defense», Constitutional Commentary, 13, 1, 1996, 91.

${ }^{36}$ En realidad, los defensores de la línea que resultaría cercana a este viejo aforismo educativo lo que sostienen es que las palabras sí pueden herir, pero que este es el precio que debemos pagar por tener derecho a nuestra libertad de expresión como personas que gozan de autonomía (L. NEWMAN, «Liberty, Community, and Censorship: Hate Speech and Freedom of Expression in Canada and the United States», op. cit., 376). Otra corriente más sofisticada, lo que hace es diferenciar las «ideas» de las «palabras» (L. ALEXANDER, «Banning Hate Speech and the Sticks and Stones Defense», op. cit., 91 en original).

${ }^{37}$ K. GelBER, Speaking Back: The Free Speech versus Hate Speech Debate, op. cit., 56.

38 Publicado póstumamente en 1962.

39 Comentado profusamente en K. GeLber, Speaking Back: The Free Speech versus Hate Speech Debate, op. cit., $52-56$.

40 Ibid., 56 y 57.

${ }^{41}$ Ibid., 57.

42 O. FIss, «El efecto silenciador de la libertad de expresión», Isonomía. Revista de Teoría y Filosofía del Derecho, 4, 1996, 17-27.

43 A. Altman, «Liberalism and Campus Hate Speech: A Philosophical Approach», Ethics, 103, 2, 302.

44 Sobre el tema de este tipo de daño, vid. K. GREENEWALT, Fighting Words: Individuals, Communities, and Liberties of Speech, Princeton, Princeton University Press, 1995, 50, y K. EGGERKING, «Australia: The Role of the Media in Perpetuating Racism», en S. Coliver (ed.), Striking a balance. Hate speech, freedom of expression and Non-discrimination, Essex: Article 19- K, 1992, 86. 
te, el hecho de deambular por la propia barriada). Y eso sin considerar efectos a más largo plazo, como la pérdida de autoestima en los intentos de ascenso social o mejora académica o profesional ${ }^{45}$.

Todo esto le ha parecido a numerosos autores como sumamente difuso ${ }^{46}$. Y a algunos les ha conducido a ver como única posible respuesta contra el hate speech al tort o la reclamación civil, basándose en una teoría del daño individualizado y de carácter injurioso (face to face $)^{47}$, pese a la problemática que suele conllevar este correoso camino procesal. El supuesto deposita la carga persecutoria sobre individuos que quizás teman represalias ${ }^{48} \mathrm{y}$ que precisamente a causa de tal miedo no quieran demandar, y desde luego, el riesgo de afrontar costes económicos más o menos elevados que en un proceso penal no estarían en juego de la misma forma. A ello súmese el asunto de la inmediatez que exija el caso al ordenamiento, pues resulta probable que no pueda aguardarse el resultado de una justicia demasiado lenta y cara.

Pero sobre todo, tal mecanismo sería insuficiente si se recoge el argumento que expongo a continuación, y que sostendría que el efecto dañino originado por el hate speech no es sólo de tipo particular, como tampoco lo es el producido por la circulación bajo los efectos del alcohol o el tráfico de moneda falsificada o el cometido contra el medio ambiente.

\section{4. ¿CUÁL DEBERÍA SER LA BARRERA DEL HATE SPEECH?}

Y es que si consideramos el tipo de sujetos contra los que se dirigiría el hate speech, es posible llegar a la conclusión de que el problema de la vulnerabilidad nos encamina a la protección, bajo cierto principio, tanto de un bien participativo como de un derecho por razón de pertenencia a colectivo. De acuerdo con la teoría sobre el lenguaje que antes se ha examinado, existiría la posibilidad de atacar aquéllos mediante la simple expresión, dependiendo mucho el éxito de tal acometida del contexto en el que se realice. Éste resultará circunscrito precisamente por los parámetros antedichos a la hora de delimitar la vulnerabilidad de ciertos sujetos: existencia o no de prejuicios arraigados contra el grupo, «visibilidad» del mismo, y atribución previa o no a sus miembros de facultades que les permitan contribuir al debate público o participar en las decisiones políticas colectivas.

El principio a proteger, pues, resulta ser el de la igualdad ${ }^{49}$; hacia él confluyen las citadas variables, que no son otra cosa que criterios para medir el grado de aproxima-

${ }^{45}$ J. WALDRON, «Dignity and defamation: The visibility of hate», op. cit., 1628.

46 R. C. Post, «Racist Speech, Democracy, and the First Amendment», William \& Mary Review, 32, 1991, 2, passim; L. AleXANDER, «Banning Hate Speech and the Sticks and Stones Defense», op. cit., passim.

47 T. MASSARO, «Equality and freedom of expression: the hate speech dilemma», William E Mary Review, 32, 2, 1991, 235, 249-250, 265; W. SADURSKI, «Racial Vilification, Psychic Harm, and Affirmative Action», en T. CAMPBell y W. SAdurSKI (eds.), Freedom of communication, Aldershot, Darmouth, 1994, 85 y 88, y también W. SADURSKI, «Offending with Impunity: Racial Vilification and Freedom of Speech», Sydney Law Review, 14, 2, 1992, 195 .

${ }^{48}$ K. GelBer, Speaking Back: The Free Speech versus Hate Speech Debate, op. cit., 1.

49 Sería un «principio en sentido estricto», de acuerdo con la noción de éste que expone RuIZ MANERO, es decir, como «norma que expresa los valores superiores de un ordenamiento»: J. RUIZ MANERO, «Principios jurídicos», en El derecho y la justicia, 2. ${ }^{a}$ ed. (1. ${ }^{a}$ ed., 1996), de E. GARZÓN VAldÉs y F. J. LAPORTA, Madrid, 
ción al mismo. El cual es a su vez premisa de la autonomía personal ${ }^{50}$. El valor de ésta, al contrario que el de la libertad formal, que se refiere sólo a conductas específicas del individuo ${ }^{51}$, versa en cambio sobre la capacidad de todo sujeto racional para conformar su voluntad de acuerdo con una evaluación crítica ${ }^{52}$. A las circunstancias, y no a las elecciones. No considerar la vulnerabilidad del grupo de adscripción supondría obviar unas cuantas condiciones de su ejercicio ${ }^{53}$. Se trataría de proteger la dignidad en el sentido de la existencia social básica de las personas, su reconocimiento como iguales ${ }^{54}$.

Asimismo, esta consideración se encuentra íntimamente relacionada con la democracia deliberativa, que admite y fomenta en su seno la articulación de razones. El debate entre sujetos libres e iguales, pues, conformaría un bien participativo a proteger, y que no puede producirse individualmente. Resulta elaborado de forma conjunta, pues comprende una actividad que no sólo requiere de varios para producir el bien, sino que es valiosa sólo por la participación común ${ }^{55}$. La deliberación democrática, sin embargo, podría ser puesta en peligro por el efecto silenciador del hate speech y las preferencias adaptativas que conlleva ${ }^{56}$, arruinando el propio derecho a la libertad de expresión de los miembros de los grupos vulnerables ${ }^{57}$. Pero los canales para que ésta se proyecte, en cualquier caso, tampoco pueden quedar libres cuando se enfrentan a conductas intimidatorias. Quien articula aquél sobre la base del insulto o la amenaza sistemáticas no parece estar reproduciendo las condiciones de la deliberación democrática, ni tampoco suministrando o intentando aportar una información ${ }^{58}$ que pudiera ayudar a adoptar opciones libremente elegidas ${ }^{59}$. Es más, lo que pretende tal individuo o grupo de ellos (en este último caso, y si estuvieran coordinados, con mayor eficacia

Trotta-CSIC, 2000, 152. Con él coincide básicamente el profesor E. ÁlvaREZ CONDE, Curso de derecho constitucional. Vol. I. El Estado constitucional. Sistema de fuentes. Los derechos y libertades, Madrid, Tecnos, 6. ${ }^{\text {a }}$ ed. (1. ${ }^{a}$, de 1992), 2008, 356-359.

50 «Ser tratado con la misma consideración y respeto, deriva asimismo de forma necesaria de la atribución de valor moral a las personas por su igual condición de agentes morales». L. HIERRO, «El concepto de justicia y la teoría de los derechos», en J. L. Colomer y E. DíAz (eds.), Estado, justicia, derechos, Madrid, Alianza, 2002,45 .

${ }_{51}$ «La libertad» a secas, sólo «se refiere a una modalidad de la acción, según la cual la persona actúa motivada por sus deseos», y, «con frecuencia nos referimos a la libertad de los actos y a la autonomía de las personas»; S. ÁlvareZ, «La autonomía personal», en J. L. COLOMER y E. DíAZ (eds.), Estado, justicia, derechos, op. cit., 160. Cursivas propias.

52 «En la medida en que las personas tienen la capacidad para evaluar críticamente y ordenar sus deseos o preferencias de acuerdo con valores, ellas son valoradas por tal capacidad y tratadas como iguales»; ibid., 170.

53 S. ÁlvareZ, «Access to Opportunities in Multicultural Societies and the Relevance of Public Expression», Social \& Legal Studies, 18, 4, 2009, 546 y 556-57.

${ }^{54} \mathrm{~J}$. WALDRON, «Dignity and defamation: The visibility of hate», op. cit., 1610.

55 Sigo la noción de D. RÈAume, «Individuals, Gropups, and Right to Public Goods», University of Toronto Law Journal, 38, 1, 1988, 10; si bien la autora aplica esta categoría a la cultura en su texto.

56 S. J. BRISON, «The Autonomy Defense of Free Speech», op. cit., 337, indica estas dos consecuencias, junto con la supresión de la autoestima en 335. Sobre ellas, vid. también J. L. MARTí, La república deliberativa, op. cit., 111.

57 Y peor aún, en este marco, sería el supuesto de que tales personas carecieran de ciertos derechos, como los de participación política, reunión, asociación, manifestación y sufragio. Al menos, en el otro supuesto, el discurso «equivocado» podría ser discutido gracias a la crítica expresada libremente.

${ }_{58}$ Por cierto, que el derecho a recibir información libre aparece en el art. 20.1.d) de nuestra CE.

$59 \mathrm{La}$ «transformación de preferencias sólo pueda producirse de manera razonada, y por tanto libre, excluyéndose las coacciones, amenazas y otro tipo de limitaciones a la libertad» (J. L. MARTí, La república deliberativa, op. cit., 95). 
todavía), es socavar la autonomía personal de los terceros pertenecientes a grupos vulnerables, merced a la creación de un clima que les baga callar.

Y también actuar o expresarse de forma diferente en ámbitos no estrictamente políticos. El derecho protegido por la prohibición del hate speech es el del aseguramiento de las condiciones básicas de desenvolvimiento de los miembros del grupo ${ }^{60}$, ese que permite conducirse libremente y sin miedo en la vida «ordinaria», es decir, en el lugar de trabajo, de ocio, cuando paseamos por las calles de una ciudad, acudimos a una celebración o ceremonia, a comprar el periódico en el quiosco o a esperar a unos amigos sentados en un parque. Todos ellos son actos que pueden ser perturbados e impedidos mediante la actuación de individuos que quieran crear una atmósfera atemorizadora. De tal manera que quedaría suprimido «el sentimiento subjetivo de seguridad respecto del conjunto de bienes jurídicos de los individuos del grupo afectado» ${ }^{61}$.

En nuestras sociedades, desgraciadamente, hay tendencias que, partiendo de premisas poco igualitarias, pretenden alimentarlas aumentando el grado de exclusión de ciertos colectivos, siendo dos de los principales, como se ha visto, la existencia de prejuicios sociales basados en estructuras de dominación y la inexistencia de la titularidad plena de derechos para determinados sujetos que viven entre nosotros. Tales son los elementos favorables a que el hate speech consiga efectos discriminatorios, y en consecuencia, factores a contrarrestar a través de ciertas medidas basadas tanto en sanciones penales, administrativas o de carácter educativo, como en políticas de reconocimiento generosas. Las propuestas excluyentes o discriminatorias que determinados grupos organizados difunden contra otros a los que quieren marginar, configuran el punto de partida para la asunción de dos principales tácticas. Herir la reputación del colectivo vulnerable de que se trate es una de ellas, atemorizarle es la otra. Ambas pueden confluir en una misma estrategia agresora, sobre todo cuando resultan coordinadas.

\section{LAS MEDIDAS CONTRA EL HATE SPEECHY SUS PROBLEMAS}

La idoneidad de las reclamaciones civiles está expuesta a las críticas ya mencionadas un poco más arriba, al margen de que no existan buenos motivos para su supresión sino, en todo caso, para advertir su insuficiencia. Por otra parte y, en general, para hablar de un daño objetivable que justifique la intervención penal hay que referirse a uno que apunte a un bien jurídico y con el suficiente grado de proximidad como para lesionarlo o ponerlo en peligro seriamente ${ }^{62}$. Junto a ambos remedios

${ }^{60}$ Sigo aquí una formulación parecida a la J. M. LANDA GOROSTIZA, La influencia penal frente a la xenofobia. Problemática general con especial referencia al delito de provocación del art. 510 del Código Penal, Bilbao, Universidad del País Vasco, 2000, 315 y 316. Lo que ocurre es que el autor piensa en su libro que en un Estado democrático como el nuestro y bajo condiciones de «normalidad» no hay un nivel de relevancia suficiente en el «grado de perturbación y en la dañosidad social que la lesión del bien jurídico entraña» (354), mientras que yo entiendo que la indefensión para el colectivo existe desde el momento en que sus miembros carecen de alguno o algunos de los derechos de la ciudadanía plena o parten de un contexto disminuyente previo.

61 J. M. Landa Gorostiza, La influencia penal frente a la xenofobia. Problemática general con especial referencia al delito de provocación del art. 510 del Código Penal, op. cit., 2000, 315 y 316. Las cursivas son propias.

62 «Aunque sean siempre frontalmente rechazables, los contenidos negativos de [...] ideas o doctrinas basadas en la discriminación o la marginación de determinados grupos y de sus integrantes como tales, no 
que combatan el hate speech, además de las sanciones administrativas que pudieran preverse, caben otros que constituirían políticas de carácter general destinadas a impedir la promoción del odio, violencia o discriminación contra ciertos grupos o la difamación o el insulto contra ellos o sus miembros. Todos ellos podrían incluirse en el ámbito del bien o del derecho, merecedores de protección y arriba mencionados, de la siguiente forma:

1) Respecto al bien participativo de la deliberación democrática. Su defensa resulta abordable de manera más adecuada en otras esferas distintas de la penal. En primer lugar incentivando una autorregulación que los medios de comunicación quisieran adoptar voluntariamente. El TEDH ya señaló, en su sentencia Observer y Guardian vs. United Kingdom, que el público tiene el derecho a recibir ideas, de acuerdo con el papel destacado que tienen tales medios en el desarrollo de una opinión pública libre ${ }^{63}$. Y ello hasta el punto reconocido por su otra resolución célebre, la del caso Jersild vs. Dinamarca, con la cual se declaró que este país había violado el art. 10 del CEDH, relativo a la libertad de expresión y de recibir y comunicar libremente opiniones e ideas, al condenar a un periodista que había introducido en un documental las declaraciones de un grupo de extrema derecha ${ }^{64}$. Pero todo esto no acaece sin entender que los mass media tienen cierta responsabilidad ante determinados contextos de tensión, como también indicó la sentencia Surek y Ozdemir vs. Turquía ${ }^{65}$.

En segundo lugar, cabe la posibilidad de dar voz a quienes habitualmente no la tienen, o bien para que el grupo al que pertenezca la víctima agredida por el hate speech pueda responder con argumentos que contribuyan a la deliberación ${ }^{66}$. Dependiendo asimismo del vehículo que hubiera tomado el discurso del odio, se adoptarían unos mecanismos u otros, en proporción con el medio elegido para su difusión perniciosa ${ }^{67}$. Este sistema evitaría la presencia directa de la víctima, sustrayéndola de cargas procesales que le obligaran a presentar una demanda. Ahora bien, aquella pertenencia no debería hacernos olvidar que aquí lo que nos importa es la libertad sustantiva de los individuos y no tanto la de los grupos, y que, como consecuencia de ello, en el caso de que éstos tiendan a estar organizados, también habría que exigirles determinados requisitos para intervenir en ese debate de respuesta. Es decir, se trataría de impedir otras vulnerabilidades de carácter transversal, instaladas en el propio colectivo del que se trate. De lo contrario, difícilmente podremos encontrar a personas legitimadas dentro de éste para responder al hate speech. Los portavoces emergerán del respeto a todos

conducen necesariamente a que la respuesta se configure penalmente en todo caso, debiendo quedar reservada la sanción penal [...] para los ataques más graves, considerando tanto el resultado de lesión como el peligro creado para los bienes jurídicos que se trata de proteger» (STS 259/2011, de 12 de abril, FD 1. ${ }^{\circ}, 1$ ). Se trata del «principio de intervención mínima del derecho penal».

${ }_{63}$ (1992) 14 EHRR 153, par. 59.

64 (1995) 19 EHRR 1.

65 (1999) 7 BHCR 339, par. 63. Algo en lo que insiste K. EKKERGING, «Australia: The Role of the Media in Perpetuating Racism» (en Striking a balance. Hate speech, freedom of expression and Non-discrimination, op. cit., 82-86) y también J. Rowвоттом, «Extreme Speech and the Democratic Functions of the Mass Media», en Extreme Speech and Democracy, op. cit.

${ }^{66}$ K. GeLber, Speaking Back: The Free Speech versus Hate Speech Debate, op. cit., 127; O. LEE, «Legal weapons for the weak? Democratizing the force of words in an uncivil society», Law E Social Inquiry, 26, 4, 2001,873 .

${ }^{67}$ K. GeLbER, Speaking Back: The Free Speech versus Hate Speech Debate, op. cit., 127. 
los miembros del grupo, de forma que existan a su vez ciertos niveles de democracia dentro de él ${ }^{68}$. De no cumplirse este principio, la idea de la respuesta discursiva de grupo queda muy debilitada.

Otro mecanismo importante para proteger el bien participativo al que me estoy refiriendo es la existencia de normas que impidan la extensión del discurso del odio en el terreno educativo. La enseñanza debe suministrar herramientas para que el individuo pueda adoptar un enfoque crítico ante la realidad que le circunda, incluida la información o los datos que le son suministrados. En este sentido, y sin alcanzar otras ambiciones desmedidas, sí resulta posible impedir que impartan clase, de manera más clara en niveles inferiores, quienes pretendan la propagación de aquel mensaje, mediante los oportunos mecanismos, administrativos o laborales, controlables siempre en última instancia de forma judicial ${ }^{69}$. Lo contrario supondría educar a los individuos en la ausencia de respeto por la dignidad de los demás, algo indispensable para cualquier democracia. De hecho, contaría con la posición preeminente en el aula del enseñante, lo cual que supondría sin lugar a dudas un nivel de coacción insoportable. La Sentencia del caso Keegstra dictada por el Tribunal Supremo de Canadá ${ }^{70}$ apunta a este extremo.

2) En relación con el derecho al aseguramiento de las condiciones básicas de desenvolvimiento del grupo vulnerable. WALDRON señala que «en el mundo real, cuando las personas demandan la clase de seguridad a la que intentan contribuir las leyes del hate speech, aquélla no versa sobre los detalles de la justicia», sino que «reside en los fundamentos [sociales] más nítidos», a saber, que «todos son igualmente humanos y que tienen la dignidad del ser humano» ${ }^{71}$. Esta reflexión sostendría su posible defensa por medio de leyes de carácter penal. En primer término, mediante la tipificación de las amenazas a grupo vulnerable (supuesto del art. 170.1 del CP español). Pero es más, también los ataques contra su honor y reputación y de carácter repetido o sistemático podrían estar socavando el mismo derecho. En este segundo caso resultaría valioso considerar, no sólo la reiteración del sujeto que profiriese las injurias o calumnias o defendiera o rehabilitase regímenes genocidas, sino también si todas estas conductas fuesen articuladas con publicidad más o menos amplia ${ }^{72}$, o a través de un mínimo complejo organizativo, pues tales circunstancias revestirían, sin duda, mayor relevancia; sin embargo, la jurisprudencia española se ha inclinado por el criterio de la incitación a la violencia para su represión penal ${ }^{73}$. En cualquier caso, y fuera de estos supuestos de la amenaza directa o la calumnia e injuria contra grupos, frente a las conductas injuriosas

${ }^{68}$ Una postura parecida expresa M. MALIK, «Extreme Speech and Liberalism», en Extreme Speech and Democracy, op. cit., 112.

${ }_{69}$ C. MCKinNON llega a proponer la expulsión de la academia de aquellos profesores que nieguen el acaecimiento del Holocausto. «Should we tolerate holocaust denial?», Res Publica, 13, 2007, 1, passim.

${ }_{70}$ R. vs. Keegstra [1990] 3 S. C. R. 697. El caso implicaba a un profesor de enseñanza media cuyas lecciones eran a menudo propaganda antisemita, ocurriendo que luego examinaba a sus alumnos sobre aquéllas y puntuaba con buena nota a quienes las habían aprendido y se mostraban de acuerdo con su contenido. Fue expulsado por tal motivo de la escuela donde enseñaba. Pese a recurrir hasta llegar a la más alta instancia del país, el Tribunal Supremo canadiense rechazó su demanda.

71 J. WALDRON, «Dignity and defamation: The visibility of hate», op. cit., 1626.

72 Ibid., 1621, habla de «la publicación y el daño hecho a los individuos y grupos a través de la desfiguración de nuestra atmósfera social por expresiones visibles, públicas y semipermanentes».

${ }^{73}$ STC 176/1995, de 11 de diciembre, FJ 5. ${ }^{\circ}$ 
face to face por motivo de pertenencia a un grupo vulnerable podría acudirse al remedio de la demanda civil propuesta, así como al de la «réplica de grupo» que defiendo y menciono en el apartado anterior.

Pero es que además, y también con un alto nivel de reprochabilidad, a veces existen conductas intimidatorias dirigidas a atacar el aseguramiento de las condiciones básicas de desenvolvimiento del grupo vulnerable, el compromiso público de tratar con igual dignidad y respeto a todos los miembros de la comunidad, y que resultan difíciles de clasificar como amenazas estrictamente y en absoluto como injurias o calumnias. Se trata de actuaciones que incitarían a terceros a concretar aquella agresión. En lugar de las amenazas típicas, resultan de carácter indirecto y se hallarían muy mediatizadas en la consecución de su objetivo por el tipo de audiencia al que se dirigieran, así como por el momento de la actuación y el alcance del medio empleado. MiLl pareció referirse a la posibilidad de este discurso cuando hablaba del orador que calentase los ánimos de una multitud hambrienta frente al establecimiento de un vendedor de grano ${ }^{74}$. Al respecto, el Tribunal Supremo estadounidense ha hablado del contexto facilitador del «peligro claro y presente» ${ }^{75}$, pero tampoco estaría de más considerar el tipo de audiencia a la cual se envíe el mensaje, como en los supuestos de menores o discapacitados. Y también, como se ha indicado en el supuesto de injurias y calumnias contra grupo, la reiteración de comportamiento y la existencia de una organización que pudiera respaldar aquellas conductas. Podría afirmarse que el bien de la seguridad de las condiciones básicas de desenvolvimiento del grupo ya está suficientemente protegido con la prohibición de la apología del genocidio o similares ${ }^{76}$, pero el problema es que aqui no nos estamos refiriendo a un colectivo en abstracto, sino especificamente a uno o varios de carácter vulnerable en un contexto social determinado, y sin tener por qué serlo sólo respecto a una lesión de bienes jurídicos tan grande como la que supone la actuación genocida. Por tanto, hablaremos de un peligro que no ha de ser tan amplio, pero sí configurar un riesgo intenso de inmersión en conductas «violentas» subsumibles en el art. 510.1 del CP español. Recordemos que esta vía, pese a quedar severamente debilitada por la STS 259/2011, de 12 de abril (caso Kalki), no fue eliminada por la STC 235/2007, de 7 de noviembre, supresora en cambio del delito de «negacionismo».

74 J. Gray y G. W. Smith (eds.), J. S. Mill On Liberty (in focus), London, Routledge, 1991, 72.

75 Doctrina inicialmente formulada por HolmES en Schenck vs. United States, 249 US 47, 52 (1919); W. SADURSKI, «Offending with Impunity: Racial Vilification and Freedom of Speech», op. cit., 184, nota 57. «La pregunta en todo caso es la de si las palabras empleadas son utilizadas en tales circunstancias o resultan de tal naturaleza como para crear un peligro claro y presente» (S. L. NeWmAN, «Liberty, Community, and Censorship: Hate Speech and Freedom of Expression in Canada and the United States», op. cit., 2002, 372). Esta doctrina fue luego completada por BRANDEIS en Whitney vs. California, 274 U. S. 357,375 (1927); S. INGBER, «The Marketplace of Ideas: A Legitimizing Myth», op. cit., 1984, 17 y 18. Lo que viene a sostener es que existe un incorrecto funcionamiento en el «mercado de las ideas» en determinadas situaciones. Tales serían aquellas en las que existiera el peligro diáfano, es decir, cuya percepción no se debiese a un temor irracional, de que se produjera de forma inminente un acto violento o hecho ilícito. Esta inmediatez, así, haría imposible la discusión típica de aquel mercado. Ibid., 17-19.

76 J. M. LANDA GOROSTIZA, La influencia penal frente a la xenofobia. Problemática general con especial referencia al delito de provocación del art. 510 del Código Penal, op. cit., 357-359 y 373, daría argumentos a favor de esta postura. 


\section{BIBLIOGRAFÍA Y ARTÍCULOS CITADOS}

Alexander, A., 1996: «Banning Hate Speech and the Sticks and Stones Defense», Constitutional Commentary, 13, 1, 71-100.

Altman, A., 1993: «Liberalism and Campus Hate Speech: A Philosophical Approach», en Ethics, 103, 2, 302-317.

ÁlvareZ, S., 2009: «Access to Opportunities in Multicultural Societies and the Relevance of Public Expression», Social E Legal Studies, 18, 4, 543-559.

Álvarez Conde, E., 2008: Curso de derecho constitucional. Vol. I. El Estado constitucional. Sistema de fuentes. Los derechos y libertades, Madrid: Tecnos, 6. ${ }^{\text {ed }}$ ed. (1. ${ }^{a}$, de 1992).

Austin, J. L., 1975: How Do Things with Words, Cambridge: Harvard University Press (2. ${ }^{\mathrm{a}}$ ed.).

BARENDT, E., 1985: Freedom of Speech, Oxford: Clarendon Press.

Betegón, J.; Laporta, F. J.; Prieto, L., y PÁramo, J. R. (eds.): Constitución y derechos fundamentales, Madrid: Centro de Estudios Constitucionales.

BrISON, S. J., 1998: «The Autonomy Defense of Free Speech», Ethics, 108, 2, 312-339.

Campbell, T., y SAdurski, W. (eds.), 1994: Freedom of communication, Aldershot: Darmouth.

CoHen, J., 1993: «Freedom of Expression», Philosophy E Public Affairs, 22, 3, 207-263.

Coliver, S. (ed.), 1992: Striking a balance. Hate speech, freedom of expression and Non-discrimination, Essex: Article 19-K.

Colomer, J. L., y DíAz, E. (eds.), 2002: Estado, justicia, derechos, Madrid: Alianza.

Delgado, R., y Stefancic, J., 1997: Must We Defend Nazis? Hate Speech, Pornography, and the New First Amendment, New York: New York University Press.

Dworkin, R., 1986: A matter of principle, Oxford: Clarendon Press (1. a ed. de 1985, Cambridge: Harvard University Press).

FeinberG, J. y Gross, H. (eds.), 1975: Philosophy of Law, Encino: Dickinson.

FISS, O., 1996: «El efecto silenciador de la libertad de expresión», Isonomía. Revista de Teoría y Filosofía del Derecho, 4, 17-27.

GeLBER, K., 2002: Speaking Back: The Free Speech versus Hate Speech Debate, Philadelphia: John Benjamins.

— 2010: «Freedom of political speech, hate speech and the argument from democracy: The transformative contribution of capabilities theory», Contemporary Political Theory, 9, 3 , 304-324.

GraY, J., y SMith, G. W. (eds.), 1991: J. S. Mill On Liberty (in focus), London: Routledge.

GreEnewalt, K., 1995: Fighting Words: Individuals, Communities, and Liberties of Speech, Princeton: Princeton University Press, London and Human Rights Centre.

Hare, I., y Weinstein, J., 2009: Extreme Speech and Democracy, New York: Oxford University Press.

InGBER, S., 1984: «The Marketplace of Ideas: A Legitimizing Myth», 1, 1-91.

JERICÓ, L., 2006: «El caso del Imán de Fuengirola: ¿auténtica comisión del delito de provocación a la violencia (art. 510.1 CP)?», Revista Penal, 18, 153-175.

Landa Gorostiza, J. M., 2000: La influencia penal frente a la xenofobia. Problemática general con especial referencia al delito de provocación del art. 510 del Código Penal, Bilbao: Universidad del País Vasco.

LEE, O., 2001: «Legal weapons for the weak? Democratizing the force of words in an uncivil society», Law E Social Inquiry, 26, 4, 847-890. 
Lippman, G., y ReDish, M. H., 1991: «Freedom of Expression and the Civic Republican Revival in Constitutional Theory: The Ominous Implications», California Law Review, 79, 2, 267 311.

MarTí, J. L., 2006: La república deliberativa, Madrid: Marcial Pons.

MASSARO, T., 1991: «Equality and freedom of expression: the hate speech dilemma», William $\varepsilon$ Mary Review, 32, 2, 211-265.

McKinnon, C., 2007: «Should we tolerate holocaust denial?», Res Publica, 13, 1, 9-28.

MeIKLejohn, A., 1948: Free Speech and its Relationship with Self-government, New York: Harper \& Row.

Nagel, T., 1995: «Personal Rights and Public Space», Philosopby E Public Affairs, 24, 83-107.

Newman, S. L., 2002: «Liberty, Community, and Censorship: Hate Speech and Freedom of Expression in Canada and the United States», American Review of Canadian Studies, 32, 3 , 369-396.

PArekH, B., 2005: «Hate speech: Is there a case for banning?», Public Policy Research, 12, 4, 213-223.

Post, R. C., 1991: «Racist Speech, Democracy, and the First Amendment», William E Mary Review, 32, 2, 267-327.

RÈAume, D., 1988: «Individuals, Gropups, and Right to Public Goods», University of Toronto Law Journal, 38, 1, 1-27.

SADURSKI, W., 1992: «Offending with Impunity: Racial Vilification and Freedom of Speech», Sydney Law Review, 14, 2, 163-195.

SCANLON, T., 1972: «A Theory of Freedom of Expression», Philosopby and Public Affairs, 1, 2, 204-226.

SCHAuer, F., 1982: Free Speech. A Philosophical Enquiry, Cambridge: Cambridge University Press.

- 1992: «Uncoupling Free Speech», Columbia Law Review, 92, 1321-1357.

SORIAL, S., 2010: «Free Speech, Autonomy and the Marketplace of Ideas», Journal of Value Inquiry, 44, 2, 167-183.

WALDRON, J., 2010: «Dignity and defamation: The visibility of hate», en Harvard Law Review, 123, 7, 1596-1667.

YONG, C., 2011: «Does Freedom of speech include hate speech?», Res Publica, 17, 4, 385-403. 